\title{
TALKING AND WRITING TO
LEARN: THE PHYSICS OF
TRAFFIC INTERSECTION
SAFETY, PART ONE
}

Matthew Perkins Coppola
Indiana University-Purdue University Fort Wayne (IPFW)

Fort Wayne, Indiana

\section{Introduction}

The practice of engaging in argument-based inquiry (Benus, Yarker, Hand, \& Norton-Meier, 2013) and argumentative writing in science (Chen, Hand, McDowell, 2013; Hand, Norton-Meier, Staker, Bintz, 2009) is a natural intersection of the Science and Engineering practices of the NGSS (National Research Council, 2013) and the Common Core State Standards for English Language Arts (National Governors Association, 2010). As Llewellyn (2012) points out, argumentation skills are vital to the preparation of a scientifically literate society. Scientific inquiry is important to the exploration and observation of science, whereas argumentation is important as gathered data is used to support evidence-based conclusions. Written argumentation is a process of making claims from data that has been reasoned through (evidence) and can be rebutted and responded to often in an iterative process to critique and construct an evidence-based understanding (Ford, 2012, Smagorinsky et al., 2010).

The argumentation framework provides an opportunity for citizens to engage in democratic discussion using principles of science to approach potentially divisive issues. Traffic intersections serve as the anchor phenomenon for this series of lessons developing scientific literacy. The investigation of this anchor phenomenon is divided into two parts. This paper deals with Part 1, in which 


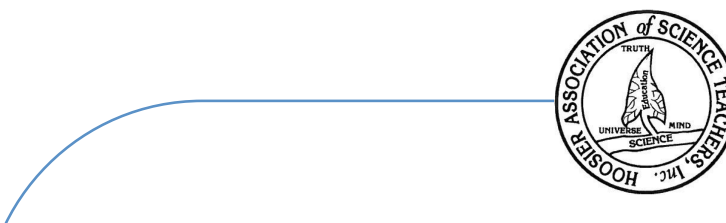

students learn to engage in scientific argumentation through mathematical modeling and analysis of real-world data collected from a traffic intersection. In Part 2, students engage in critical reading in order to participate in argumentative writing by using evidence to defend a formal position on the use of traffic cameras.

My inspiration for this investigation is situated in my experiences as a high school physics teacher. The class went out to the heavily trafficked road in front of the school and used meter sticks and stopwatches to measure the speed of passing cars. The speed limit on the road was a brisk 40 miles per hour unless the yellow school zone lights blinked the warning that passing cars needed to reduce their speed to 25 miles per hour. We recorded some cars racing through at speeds exceeding the limit while others; perhaps confused by the presence of the students along the sidewalk, slowed down to the lower limit.

Independent of our observations, civic leaders recognized that excessive speeding and red light violations were evident along several roads in the community. The city council responded by voting to install speed or red-light cameras at four key locations. Video and radar data from the surveillance cameras were used by law enforcement to issue traffic tickets to violators. Opposition grew quickly, and segments of the community passionately organized to protest. The heated and polarized debates surrounding the traffic cameras suffered from a lack of information and research. Opinions, rather than evidence, dominated the conversation. I realized that this situation was a good opportunity to empower my students lead an evidence-based conversation using the principles of physics.

I designed a unit in which students (1) developed and applied mathematical models to traffic intersections in their neighborhoods and (2) used argumentative processes to state an evidence-based recommendation on the use of cameras at traffic intersections. This article focuses on the first half of this unit: mathematical modeling and its application to the students' communities. A second article in an upcoming issue will outline my approach to integrating argumentative writing into the physics classroom. 
The lessons in Part 1 of this unit were heavily influenced by the modeling approach described in Eisenkraft's (2010) textbook, Active physics: A projectbased inquiry approach. My lesson sequence uses the 5E model of instruction (Bybee, 1997) as a framework for learning.

\section{Part 1: Modeling Traffic Intersections Engage (20 minutes)}

Students begin with a short writing prompt:

Explain how you make the decision whether to stop or continue through a traffic intersection when the signal light turns yellow.

During the whole class conversation that follows, students identify three reactions to the changing light: slow to a stop, continue traveling at the current rate of speed, or speed up.

The driver has to first recognize the light is yellow and then make a decision about whether to stop or to proceed. I ask students:

Estimate how much time it takes to make the decision to stop, continue, or speed up and label this the decision time $\left(t_{d}\right)$.

Students are then asked what other variables the driver must consider. Students offer the speed of the car (v), the length of the time the light is yellow $\left(t_{y}\right)$, the braking acceleration of the car (a), the width of the intersection (w), and the distance the vehicle is from the intersection $\left(x_{i}\right)$. Students also mention the weather, presence of children, density of traffic, and type of vehicle they are driving. I have students record the key variables and its symbol in their notebooks for later use.

We have a whole-class discussion to describe the likely motion of a car throughout each of the three outcomes. As students elicit their prior understanding they discuss how a driver makes a decision and the plausible variables for any given intersection. Discussion transitions to consider the motion of the car as they are making a decision. I ask students:

Describe the motion of the car as the driver makes their decision.

Most students realize the car will maintain constant motion (speed) while they think. This detail is important for building a mathematical model in the next segment of the lesson. 


\section{Explore (40 minutes)}

During this segment of the lesson students work in groups of three or four students to model traffic intersections; first using drawings and later using mathematical equations. Each group is handed a toy car and a large piece of paper (at least 11"x14") and instructed to draw a four-way traffic intersection with a traffic light (Figure 1). I then introduce the students to the idea of GO Zones and STOP Zones. These mathematical constructs are helpful to traffic engineers in making decisions about the length of time a light should be yellow and the proper speed limit to assign to a road.

\section{Figure 1: Sample student drawing of traffic intersections}

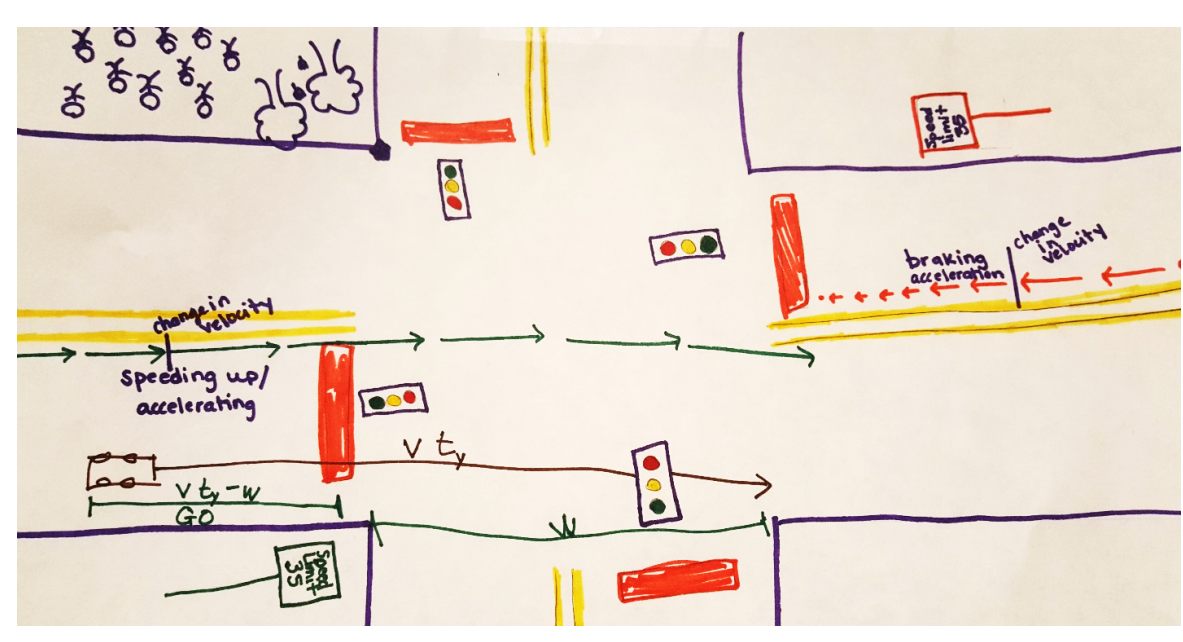

A car already in the GO Zone as the light turns yellow is able to safely travel through the intersection, without accelerating, before the light changes to red. A driver positioned in the STOP Zone is able to safely brake to a stop before reaching the intersection. 


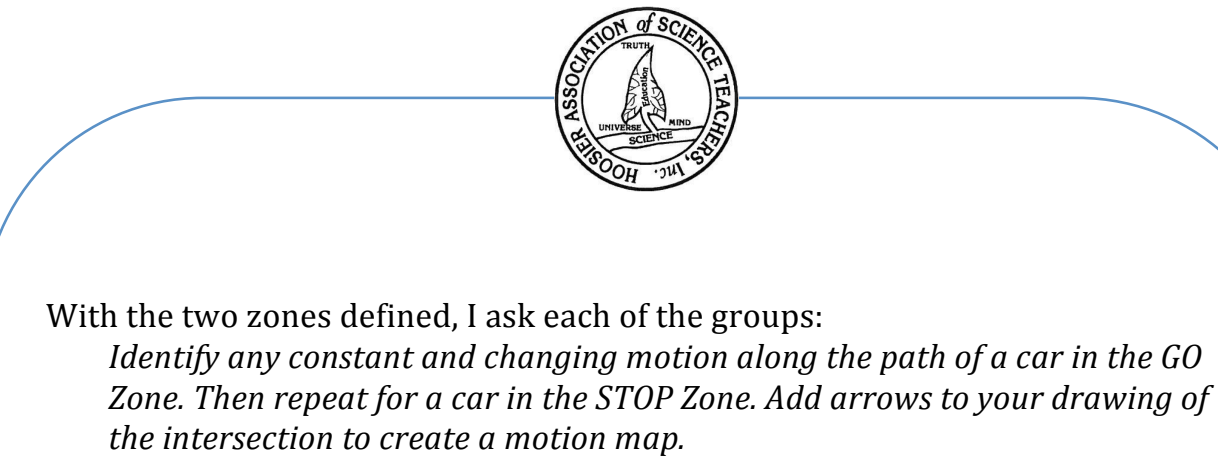

Assume the car in the GO Zone travels at a constant rate of motion all the way through the intersection. Assume the driver in the STOP Zone maintains a constant rate of motion while reacting and once the brakes are applied, the car experiences a changing rate of motion, slowing to a stop

As I circulate among the groups I encourage them to play with the physical model (car and drawing). After this segment of guided play, students should be thinking in terms of constant and changing velocities. I challenge my students to use the variables identified in the engage phase of the lesson to derive mathematical equations to determine the boundaries of the GO Zone and the STOP Zone. The simplest solutions to this challenge are provided in detail in Appendix A and Appendix B.

Once students have grappled with deriving an equation that works, I provide a sample set of data to each group and ask them to calculate the boundaries of the GO and STOP Zones and use graph paper to make a scaled drawing of each. Groups must decide whether the fictional intersection is safe for drivers and write a short explanation of how they came to that decision.

\section{Explain (30 minutes)}

Each group makes a short presentation to the class, sharing their drawings, explaining how they derived their equations, and discussing the safety of the traffic intersection. As the students share their ideas about whether or not a traffic intersection is safe, a pattern emerges from the given data. The provided data sets were set up so that the GO and STOP zones overlap for some intersections and have gaps between them in others. Traffic engineers refer to these as Dilemma Zones and/or Overlap zones (Gazis et al., 1960, see Figure 2). Traffic engineers consider an intersection with an Overlap zone to be safe, while a Dilemma zone leaves some cars unable to stop or continue through safely. 
Figure 2: Overlap and Dilemma zones.
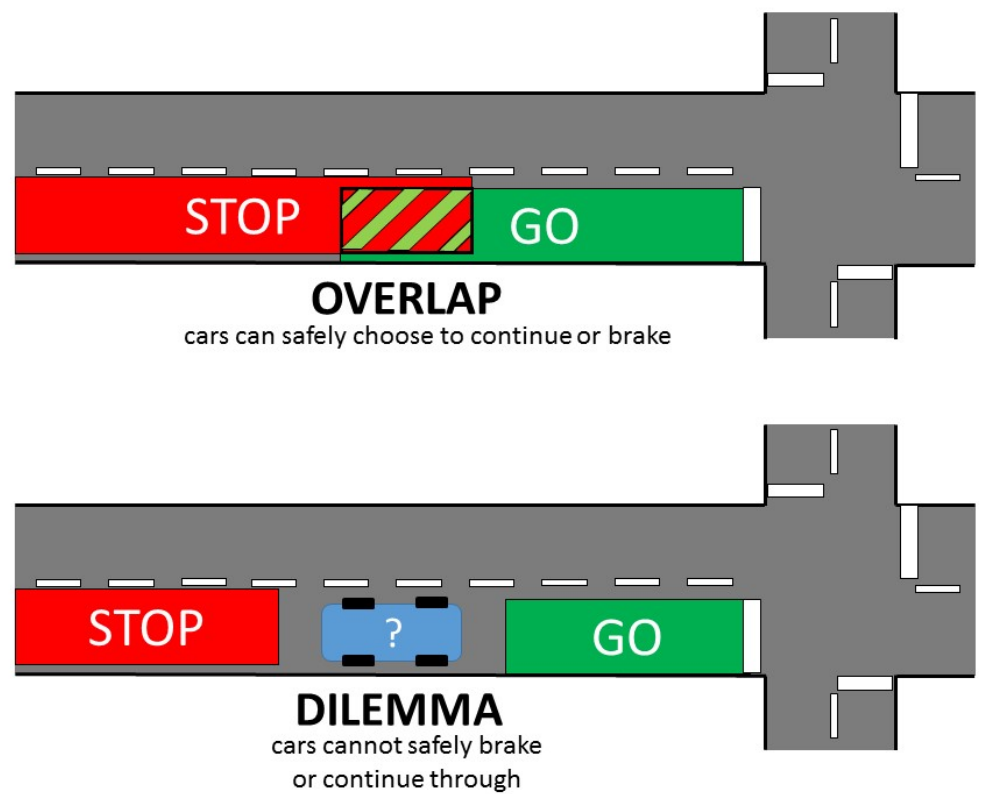

Students generally agree that Dilemma zones are dangerous, since a car could find itself in a position in which it can neither safely brake nor safely continue through the intersection. Some students perceive Overlap zones as dangerous since a car that could either stop or proceed might confuse drivers behind them. Because the STOP Zone is dependent on the driver's reaction time there is no absolute or optimal size for an Overlap zone. In practice, traffic engineers set the length of the yellow light time based on an average reaction time of $1.0 \mathrm{~s}$, speed limit, grade of the road, and braking acceleration of $-3.1 \mathrm{~m} / \mathrm{s}^{2}$ (Pline, 1999).

As the Explain phase of the lesson ends I want the students acutely aware of how the GO and STOP zones interact to create Dilemma and Overlap zones. In 


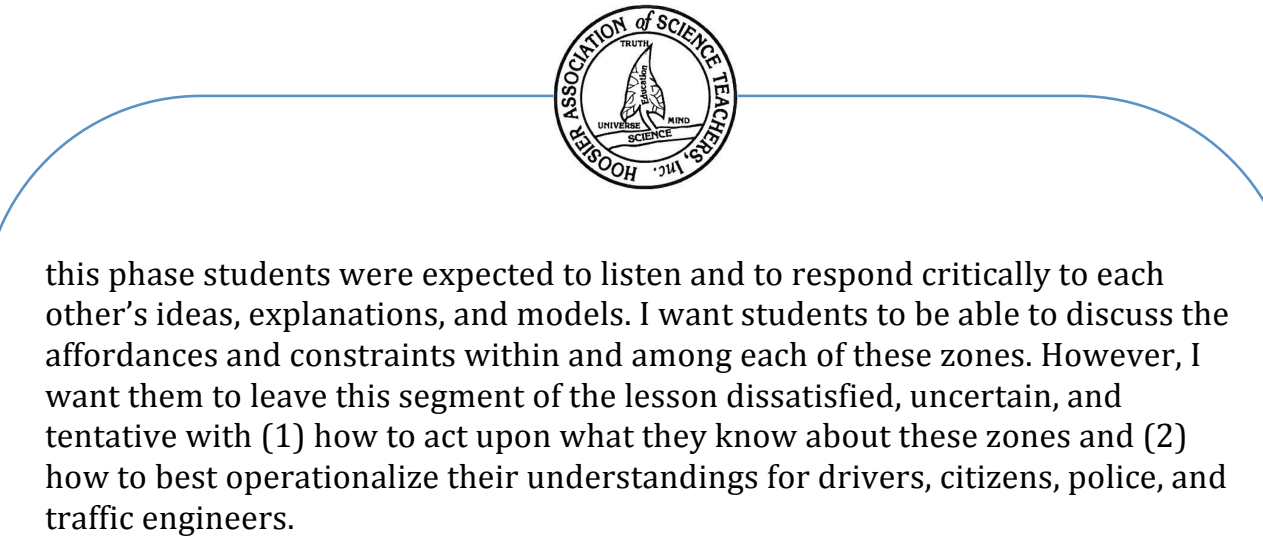

\section{Elaborate (30 minutes + one week out of class)}

The elaborate phase of the lesson is about applying information in new but familiar ways. At this point students are well informed about each of these zones. I offer them the following challenge:

After examining a traffic intersection in our neighborhood during a yellow light determine the extent to which it is safe for pedestrians and can foster safe and law-abiding decision-making by drivers.

I regroup the students, as best I can, so they are with other students in or near their neighborhood. Their assignment is to be completed outside of class as students investigate traffic intersections near their homes. Students are given strict instructions to choose a traffic intersection (1) with a speed limit of 35 mph or less and (2) well-marked crosswalks. Before data collection, students must decide how they will measure the width of the intersection and yellow light time. They must also decide how they will estimate the driver's decision time. I tell students to assume a braking acceleration of $-5.0 \mathrm{~m} / \mathrm{s}^{2}$.

Students are given a few minutes in class to talk about how they could measure and estimate. If available, students bring up a satellite image of the interaction (e.g. maps.google.com) to help them to recall the intersection. The group then reports to the class how they will measure and estimate their data sources. Once the group's approach is presented, discussed, and approved they can begin the data collection process.

I provide students a presentation rubric to make them aware of what their presentation must address and to clarify expectations (see Appendix C). I give students the option of preparing a cardboard poster, a paper handout, or a digital presentation to assist them in sharing their findings. 
Students on their own time visit the intersection. I find that one week is a reasonable time frame for collecting, analyzing, and assembling a presentation to share with the class. In the presentation, students provide (1) photo of the intersection, (2) procedure for how they collected data, (3) data they collected, (4) scaled diagram showing the GO and STOP zones, (5) determination of the safety of the intersection for pedestrians and (6) if the intersection is safe and promotes law-abiding decision-making by drivers.

I want students to leave this part of the lesson ready and able to offer and make informed decisions because they have negotiated meaning through thinking, talking, listening, modeling, and presenting ideas for other to challenge and critique.

\section{Evaluate (5-10 minutes per group, depending on class size)}

How students express results, draw conclusions, receive recommendations on their own presentation, and evaluate the presentations of others are essential components for measuring student learning. Evaluation begins informally at the beginning of the unit and is continuous throughout. Formal evaluation takes place for each student (1) during their group's presentation, (2) during Q \& A session after each presentation, and (3) after my evaluation of their written feedback to others and their own self-reflection of the experience.

During the Elaborate phase I provided students a copy of the presentation rubric (see Appendix C). The rubric serves as a checklist of sorts to help students to understand what information I expect them to share with the group.

Students formally present their findings to their classmates. In the spirit of promoting good citizenship and community involvement, students are encouraged to invite members of the community to attend, including city council members and others from local government. I help students, as needed, with invitations. Following each presentation, the audience (students and guests) have the opportunity to ask questions.

We brainstorm the sorts of questions we (other students, guests, and myself) might like to ask a group during or after their presentation. This helps groups to be forward thinking in what and how they present. Figure 3 provides some sample questions. 


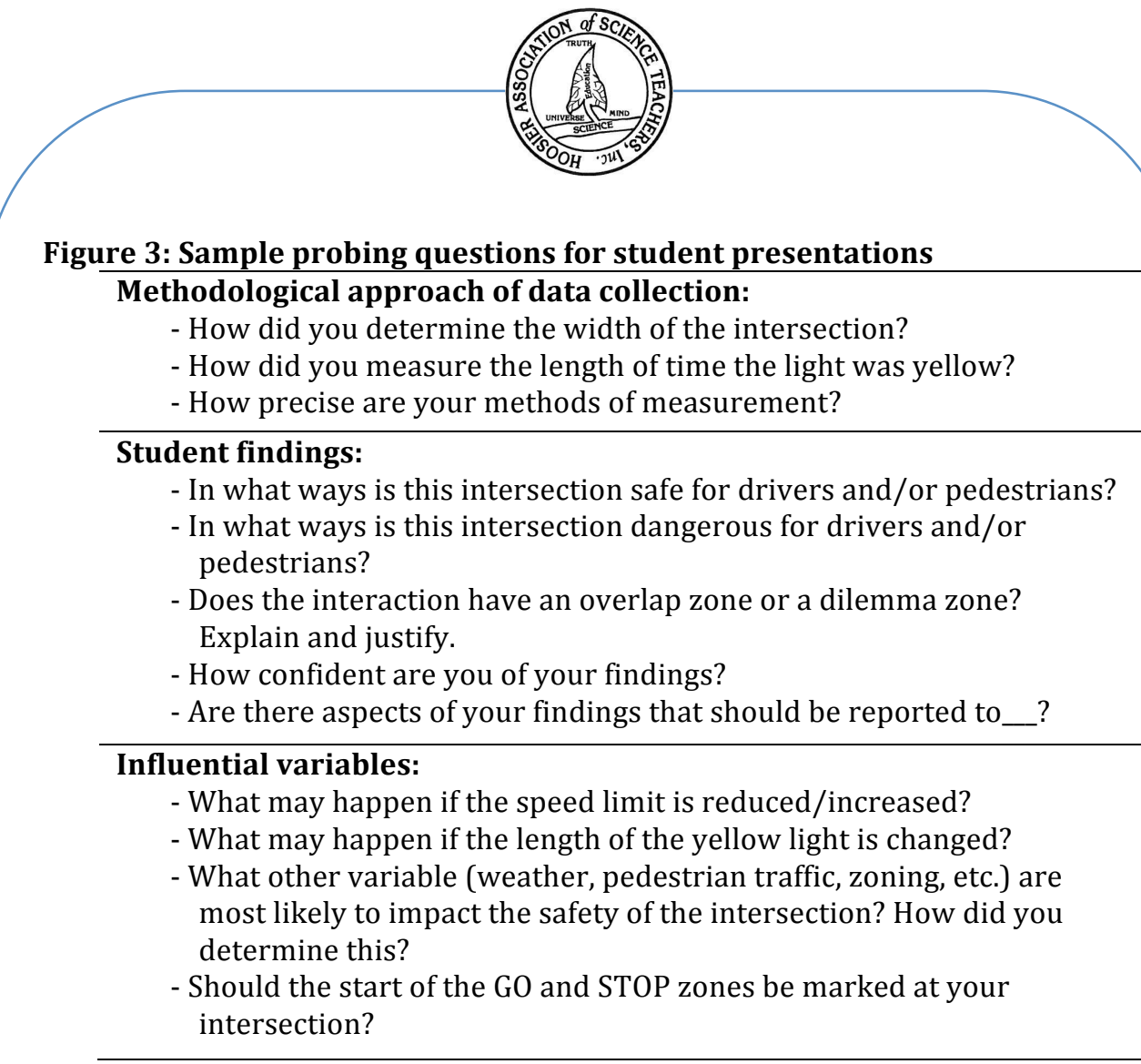

The student presentations represent an evidence-based judgment on the safety of a traffic intersection. It is especially important for students to consider the ramifications of a poorly completed presentation and discussion. Questions serve to assess students' understanding of how each of the variables in the model impacts the results. For example, a short overlap zone could easily become a dilemma zone if weather conditions changed the decision time or braking acceleration.

Each group presentation is assessed by peer groups, myself, and a selfreflection. Peer groups assess the presentation using the rubric and provide a few sentences of feedback. I also assess the presentation and provide feedback. After receiving peer and teacher feedback, each student reflects on their experience in a short structured writing. The student discusses the contributions they made to their group, their confidence in their conclusions, 


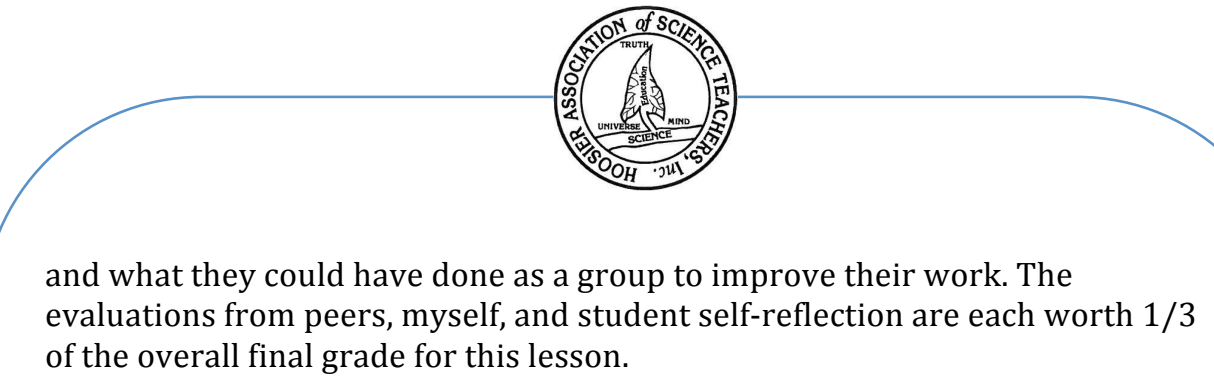

\section{Discussion}

Precisely because traffic intersections are an everyday part of our lives, they provide a rich and relevant context for students to develop their understanding of motion and to engage in several scientific practices. Whether in an urban, suburban, or rural setting, traffic intersections are a way people have adapted their environment to their needs. A healthy appreciation of this environment is critical to the safety of those learning or about to learn how to drive.

In the first half of this unit, students talked in small groups and engaged in whole-class dialogue to build a conceptual model applicable to a real-life situation. They collected data, drew evidence-based conclusions, and shared their findings with their school-aged peers and members of the community. These lessons align with multiple science and literacy standards, as evidenced in Table 1.

At the end of this first sequence of lessons, students better understand how to make an informed decision about whether to stop or continue when a traffic light turns yellow. Students reflect on the impact weather or distractions can have on personal safety. Students are also trained to critically evaluate the safety of a traffic intersection. Rather than being blindly frustrated that an intersection in the community seems to be dangerous, students can take an active role in assessing the degree to which it may be unsafe. Future discourse on traffic safety is elevated.

\section{Part Two Lesson}

Part Two of this lesson further develops students' literacy skills in the areas of critical reading and writing. Students apply their scientific knowledge and basic argumentation skills to determine the safety of a single traffic intersection. Students learn how to critically read scholarly journal articles and construct a formal written argument. Students will broaden the scope of their argument from a single intersection to the best practices for enforcement of traffic laws. Moving past emotionally-charged opinions, students use scientific evidence to inform and establish an evidence-based position on the use of cameras to impact the behavior of motorists. 


\section{Table 1: Lesson Alignment to Indiana Standards (2016)}

\begin{tabular}{|c|c|c|c|}
\hline $\begin{array}{l}\text { Integrated Chemistry \& Physics } \\
\text { Standards (IDOE) }\end{array}$ & AP Physics 1 Standards (IDOE) & $\begin{array}{l}\text { Science and } \\
\text { Engineering } \\
\text { Process } \\
\text { Standards } \\
\text { (IDOE) }\end{array}$ & $\begin{array}{l}\text { Literacy in Science/ } \\
\text { Technical Subject } \\
\text { standards (IDOE) }\end{array}$ \\
\hline $\begin{array}{l}\text { ICP.1.1 } \\
\text { Develop graphical, mathematical, } \\
\text { and pictorial representations (such } \\
\text { as a motion map) that describe the } \\
\text { relationship between the clock } \\
\text { reading (time) and position of an } \\
\text { object moving at a constant velocity } \\
\text { and apply those representations to } \\
\text { qualitatively and quantitatively } \\
\text { describe the motion of an object. } \\
\text { ICP.1.4 } \\
\text { Distinguish between the terms } \\
\text { "speed," "velocity," average speed," } \\
\text { and "average velocity" and } \\
\text { determine the value of any of these } \\
\text { measurements given either a } \\
\text { graphical or mathematical } \\
\text { representation. } \\
\text { ICP } 2.1 \\
\text { Develop graphical, mathematical, } \\
\text { and pictorial representations (such } \\
\text { as a motion map) that describe the } \\
\text { relationship between the clock } \\
\text { reading (time) and velocity of an } \\
\text { object moving at a constant } \\
\text { acceleration and apply those } \\
\text { representations to qualitatively and } \\
\text { quantitatively describe the motion } \\
\text { of an object in terms of its change } \\
\text { in position or velocity. }\end{array}$ & $\begin{array}{l}\text { PI.1.1 } \\
\text { Develop graphical, } \\
\text { mathematical, and pictorial } \\
\text { representations (e.g. a motion } \\
\text { map) that describe the } \\
\text { relationship between the clock } \\
\text { reading (time) and position of } \\
\text { an object moving at a uniform } \\
\text { rate and apply those } \\
\text { representations to } \\
\text { qualitatively and } \\
\text { quantitatively describe the } \\
\text { motion of an object. } \\
\text { PI.1.4 } \\
\text { Describe the differences } \\
\text { between the terms "distance," } \\
\text { "displacement," "speed," } \\
\text { "velocity," "average speed," } \\
\text { and "average velocity" and be } \\
\text { able to calculate any of those } \\
\text { values given an object moving } \\
\text { at a single constant velocity or } \\
\text { with different constant } \\
\text { velocities over a given time } \\
\text { interval. } \\
\text { PI.2.1 } \\
\text { Develop graphical, } \\
\text { mathematical and pictorial } \\
\text { representations (e.g. a motion } \\
\text { map) that describe the } \\
\text { relationship between the clock } \\
\text { reading (time) and velocity of } \\
\text { an object moving at a } \\
\text { uniformly changing rate and } \\
\text { apply those representations to } \\
\text { qualitatively and } \\
\text { quantitatively describe the } \\
\text { motion of an object. }\end{array}$ & $\begin{array}{l}\text { SEPS.2 } \\
\text { Developing and } \\
\text { using models } \\
\text { and tools } \\
\text { SEPS.3 } \\
\text { Constructing } \\
\text { and performing } \\
\text { investigations } \\
\text { SEPS.4 } \\
\text { Analyzing and } \\
\text { interpreting } \\
\text { data } \\
\text { SEPS.5 } \\
\text { Using } \\
\text { mathematics } \\
\text { and } \\
\text { computational } \\
\text { thinking } \\
\text { SEPS.7 } \\
\text { Engaging in } \\
\text { argument from } \\
\text { evidence } \\
\text { SEPS.8 } \\
\text { Obtaining, } \\
\text { evaluating, and } \\
\text { communicating } \\
\text { information }\end{array}$ & $\begin{array}{l}\text { 11-12.LST.7.1 } \\
\text { Conduct short as } \\
\text { well as more } \\
\text { sustained research } \\
\text { assignments and } \\
\text { tasks to answer a } \\
\text { question (including } \\
\text { a self-generated } \\
\text { question), test a } \\
\text { hypothesis, or solve } \\
\text { a problem; narrow } \\
\text { or broaden the } \\
\text { inquiry when } \\
\text { appropriate; } \\
\text { synthesize multiple } \\
\text { sources on the } \\
\text { subject, } \\
\text { demonstrating } \\
\text { understanding of } \\
\text { the subject under } \\
\text { investigation. }\end{array}$ \\
\hline
\end{tabular}




\section{References}

Benus, M.J., Yarker, M.B., Hand, B.M. \& Norton-Meier, L.A. (2013). Analysis of discourse practices in elementary science classrooms using argument- based inquiry during whole-class dialogue. In M. Khine \& I. Saleh (Eds.), Approaches and Strategies in Next Generation Science Learning (pp. 224-245). Hershey, PA: Information Science Reference.

Bybee, R.W. 1997. Achieving Scientific Literacy. Portsmouth, N.H.: Heinemann.

Chen, Y.-C., Hand, B. \& McDowell, L. (2013). The effects of writing-to-learn activities on elementary students' conceptual understanding: learning about force and motion through writing to older peers. Science Education, 97, 745771.

Eisenkraft, A. (2010). Active physics: A project-based inquiry approach. Armonk, New. York: It's About Time, Herff Jones Education Division.

Ford, M. J. (2012). A dialogic account of sense-making in scientific argumentation and reasoning. Cognition and Instruction, 30, 207-245.

Gazis, D., Herman, R., \& Maradudin, A. (1960). The problem of the amber signal light in traffic flow. Operations Research, 8(1), 112-132.

Hand, B., Norton-Meier, L., Staker, J. \& Bintz, J. (2009). Negotiating Science: The Critical Role of Argument in Student Inquiry. Portsmouth, NH: Heinemann.

Llewellyn, D.L., (2012). Teaching high school science through inquiry and argumentation (2nd ed.). Newbury Park, CA: Corwin.

National Governors Association. (2010). Common core state standards. National Research Council. (2013). Next Generation Science Standards: For States, By States. Washington, DC: The National Academies Press.

Pline, J. L. (Ed.). (1999). Traffic engineering handbook (5th ed.). Washington, DC: Institute of Transportation Engineers.

Smagorinsky, P., Johannessen, L., Kahn, E., \& McCann, T. (2010). The dynamics of writing instruction: A structured process approach for middle and high school. Portsmouth, NH: Boynton/Cook. 


\section{Appendix A: Derivation of the GO Zones}

Based on Eisenkraft, A. (2010). Active physics: A project-based inquiry approach. Armonk, New. York: It's About Time, Herff Jones Education Division.

Note: Because the cars are traveling in one dimension and not changing direction, the magnitude of the displacement is equal to the distance. For simplicity of writing, I will refer to the displacements as distances.

Derivation of the GO Zone

The GO Zone is defined as the range of positions a car can be from the white stop line of a traffic intersection and make it completely to the other side before the light turns red.

The farthest position away from the white stop line is determined by (1) the velocity of the car $(v)$, assumed to be traveling the speed limit, (2) the length of time $\left(t_{y}\right)$ the light is yellow, and (3) the width $(w)$ of the traffic intersection to be crossed.

The car at this farthest position that can safely cross travels a distance equal to the product of the velocity and the yellow light time

(1) $\mathrm{D}=v t_{y}$

This is the total distance the car travels. The GO Zone is defined not from the other side of the intersection but instead from the white stop line before the car enters the intersection. Thus the width of the intersection $(w)$ must be subtracted.

(2) GO Zone $=\mathrm{D}-\mathrm{w}$

(3) GO Zone $=v t_{y}-w$

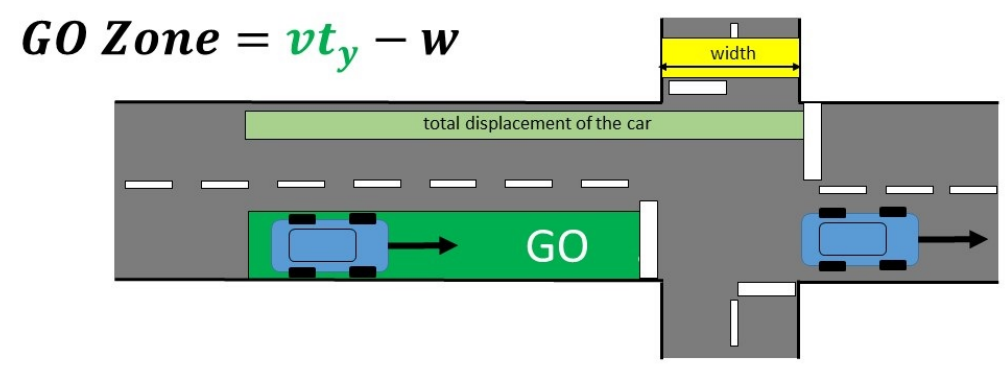




\section{Appendix B: Derivation of the STOP Zone}

Based on Eisenkraft, A. (2010). Active physics: A project-based inquiry approach. Armonk, New. York: It's About Time, Herff Jones Education Division.

The STOP Zone is defined as the closest a car can be to the white stop line of a traffic intersection and still come to a complete stop using normal braking. This closest car travels a distance $\left(\mathrm{D}_{\mathrm{T}}\right)$ at a constant velocity $(v)$ while thinking about breaking, then travels a distance $\left(D_{B}\right)$ while braking the vehicle to a stop.

(1) STOP Zone $=D_{T}+D_{B}$

While the driver is deciding whether to brake, the car travels with velocity $v$ for time $t_{d}$

(2) $\mathrm{D}_{\mathrm{T}}=v t_{d}$

After the driver decides to brake, the car accelerates to a stop. Since the initial velocity $(v)$ of the car is determined to be positive, the acceleration $(a)$ of the car must be negative in order for the car to stop

$\left(\mathrm{v}_{\mathrm{f}}=0\right)$. Based on the variables the students considered important for braking, I chose the following kinematic equation

(3) $\mathrm{vf}_{\mathrm{f}}^{2}=\mathrm{vi}^{2}+2 \mathrm{a} \Delta \mathrm{x}$

Substitute the initial and final velocities and the braking acceleration into the kinematic equation

(4) $0=v^{2}+2 a D_{B}$

Subtract $v$ from both sides and divide by $2 a$ to solve for $D_{B}$

(5) $\mathrm{D}_{\mathrm{B}}=-v^{2} / 2 a$

Substituting the values for $\mathrm{D}_{\mathrm{T}}$ and $\mathrm{D}_{\mathrm{B}}$ into equation (1)

(6) STOP Zone $=v t_{d}-\mathrm{v}^{2} / 2 \mathrm{a}$

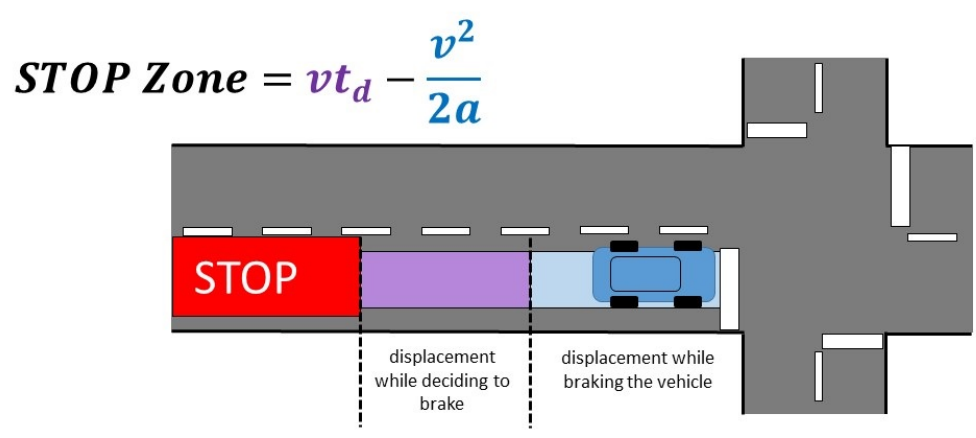




\section{Appendix C: Presentation Rubric}

\begin{tabular}{|c|c|c|c|}
\hline & 2 & 1 & 0 \\
\hline $\begin{array}{l}\text { Site } \\
\text { selection }\end{array}$ & $\begin{array}{l}\text { Traffic intersection has a } \\
\text { maximum speed limit of } 35 \mathrm{mph} \\
\text { or less. Multiple pictures are } \\
\text { included. }\end{array}$ & $\begin{array}{l}\text { Traffic intersection has a speed } \\
\text { limit of } 40 \text { mph or only one } \\
\text { picture is included. }\end{array}$ & $\begin{array}{l}\text { Traffic intersection has a speed } \\
\text { limit of } 45 \mathrm{mph} \text { or higher or } \\
\text { pictures were not included. }\end{array}$ \\
\hline $\begin{array}{l}\text { Procedure } \\
\text { for data } \\
\text { collection }\end{array}$ & $\begin{array}{l}\text { Width of intersection and yellow } \\
\text { light time are determined. } \\
\text { Methods for determining each } \\
\text { are explicitly explained. Values } \\
\text { for each are reasonable. }\end{array}$ & $\begin{array}{l}\text { Width of intersection and yellow } \\
\text { light time are determined. } \\
\text { Methods for determining each } \\
\text { are vague or values for each are } \\
\text { unreasonable. }\end{array}$ & $\begin{array}{l}\text { Width of intersection and yellow } \\
\text { light time are omitted or } \\
\text { otherwise appear to be falsified. }\end{array}$ \\
\hline Estimation & $\begin{array}{l}\text { Decision time is reasonably } \\
\text { estimated, no shorter than } 0.2 \\
\text { seconds and no longer than } 1.5 \mathrm{~s} \text {. } \\
\text { Estimation of decision time is } \\
\text { logically explained. }\end{array}$ & $\begin{array}{l}\text { Decision time is shorter than } 0.2 \\
\text { seconds or longer than } 1.5 \\
\text { seconds or the estimation of } \\
\text { decision time is not explained. }\end{array}$ & $\begin{array}{l}\text { Determination of decision time is } \\
\text { not explicitly stated. }\end{array}$ \\
\hline $\begin{array}{l}\text { Data } \\
\text { calculations }\end{array}$ & $\begin{array}{l}\text { Data are converted to metric } \\
\text { units. GO and STOP zones are } \\
\text { correctly determined from } \\
\text { recorded data. All calculations } \\
\text { are shown in detail. Values for } \\
\text { each zone is realistic. }\end{array}$ & $\begin{array}{l}\text { Units for measurements are } \\
\text { mixed or one of the zones (GO or } \\
\text { STOP) are incorrectly calculated } \\
\text { from listed data or calculations of } \\
\text { GO and STOP zones are not } \\
\text { shown. }\end{array}$ & $\begin{array}{l}\text { Both GO and STOP zones are } \\
\text { incorrectly calculated using listed } \\
\text { data. }\end{array}$ \\
\hline $\begin{array}{l}\text { Data } \\
\text { analysis }\end{array}$ & $\begin{array}{l}\text { GO and STOP zones, as } \\
\text { calculated, are correctly plotted } \\
\text { to scale. Intersection is correctly } \\
\text { interpreted as an OVERLAP or } \\
\text { DILEMMA zone. }\end{array}$ & $\begin{array}{l}\text { GO and STOP zones are plotted } \\
\text { incorrectly or the intersection is } \\
\text { incorrectly evaluated as } \\
\text { OVERLAP or DILEMMA }\end{array}$ & $\begin{array}{l}\text { GO and STOP zones are not } \\
\text { plotted } \text { or the intersection is not } \\
\text { evaluated as OVERLAP or } \\
\text { DILEMMA. }\end{array}$ \\
\hline $\begin{array}{l}\text { Pedestrian } \\
\text { safety }\end{array}$ & $\begin{array}{l}\text { Features of the intersection are } \\
\text { correctly used to determine the } \\
\text { safety for pedestrians. }\end{array}$ & $\begin{array}{l}\text { Some features are used to } \\
\text { determine the safety of the } \\
\text { intersection but not convincingly. }\end{array}$ & $\begin{array}{l}\text { Pedestrian safety is either not } \\
\text { discussed or not supported } \\
\text { correctly with evidence. }\end{array}$ \\
\hline Conclusion & $\begin{array}{l}\text { Conclusion summarizes the data } \\
\text { analysis, including GO and STOP } \\
\text { zones, and explains the degree to } \\
\text { which the intersections are safe } \\
\text { or unsafe based on the size of the } \\
\text { OVERLAP or DILEMMA zone. }\end{array}$ & $\begin{array}{l}\text { Conclusion fails to include details } \\
\text { from the data analysis in its } \\
\text { determination of the safety of the } \\
\text { intersection }\end{array}$ & No conclusion is provided \\
\hline Diagrams & $\begin{array}{l}\text { Diagrams are scaled, easy to } \\
\text { read, and labeled appropriately. }\end{array}$ & $\begin{array}{l}\text { Diagrams are readable and } \\
\text { provide most of the requested } \\
\text { information }\end{array}$ & $\begin{array}{l}\text { Diagrams are difficult to read, } \\
\text { confusing, or absent from the } \\
\text { presentation. }\end{array}$ \\
\hline Quality & $\begin{array}{l}\text { Presentation exceeds } \\
\text { expectations for content and } \\
\text { clarity. Presenters handled } \\
\text { questions from the teacher and } \\
\text { peers exceptionally well. }\end{array}$ & $\begin{array}{l}\text { Presentation meets expectations } \\
\text { for content and clarity. } \\
\text { Presenters answered most } \\
\text { questions from the teacher and } \\
\text { their peers correctly. }\end{array}$ & $\begin{array}{l}\text { Presentation failed to meet } \\
\text { expectations for either content or } \\
\text { clarity. Presenters failed to be } \\
\text { able to answer appropriate } \\
\text { questions from the teacher or } \\
\text { their peers. }\end{array}$ \\
\hline
\end{tabular}

\section{APA reference for this article:}

Perkins Coppola, M. (2018). Talking and writing to learn: The physics of traffic intersection safety, part one. The Hoosier Science Teacher 41(1), 6-20. Doi: $10.14434 /$ thst.v41i123677 